\title{
Professor Heisuke Hironaka's Contribution in Promoting Mathematical Sciences and Bringing up Talent in New Generations
}

\author{
By
}

Tadao ODA

In addition to his great accomplishments in mathematical research itself, Professor Hironaka has been very active since 1980 in trying to promote mathematical sciences and to bring up young mathematical scientists. His accomplishments in these respects are considerable as explained below.

His motivations for these activities and initial challenges he had to overcome are described in his own words in

H. Hironaka: Fame, sweet and bitter, in Miscellanea Mathematica, Festschrift for Heinz Götze (P. Hilton, F. Hirzebruch, R. Remmert, eds.), ISBN 3-540-54174-8, Springer-Verlag, 1991, pp.155-176.

Here are gists of some of the later developments and major accomplishments:

\section{Japan Association for Mathematical Sciences (JAMS)}

JAMS is a foundation established on December 4, 1984 under the approval of the Ministry of Education, Science and Culture of the Japanese Government. Its aim is to promote mathematical sciences through research grants and international academic exchange.

It was no trivial matter then and until recently to establish a foundation with ministerial-level approval in Japan. One of the prerequisites was to secure the endowment of at least 100,000,000 Yen without any favorable treatment in taxation. Only after successful activities for several years, the foundation was to become eligible for special tax-exempt status that makes fund-raising much easier through tax waiver for the donors. Even if this special status was granted, however, it lasted for only two years. For renewal the foundation was to undergo strict review of its activities during the past two-year period.

These difficulties could not have been overcome in the case of JAMS without recognition and admiration of academic achievements and personality Pro-

(C) 2008 Research Institute for Mathematical Sciences, Kyoto University. All rights reserved. 
fessor Hironaka enjoyed among many people in the government, business community and academia.

The tax-exempt status of JAMS was very helpful in the preparation for the International Congress of Mathematicians 1990 held in Kyoto.

From 1984 through 2006, JAMS awarded well over 100,000,000 Yen in total as research grants, research scholarship and fellowship grants. Regarding travel grants for Japanese to go overseas and to invite researchers from overseas, the roles JAMS played were crucial until very recently when the Japanese Government began allowing its Grants-in-Aid for Scientific Research to be used for international academic exchange. Separate grants for international academic exchange have been available from the Japan Society for the Promotion of Science, but the applications had to be submitted way in advance, while JAMS was more flexible in this respect.

Aside from the grants through applications mentioned above, JAMS took initiative in the following activities among others:

- 1,000,000 Yen grant each year since 1996 to Institut des Hautes Études Scientifique in France to be used as stipend/travel for visitors from Japan,

- 1,000,000 Yen grant each year since 1996 to Mathematisches Forschungsinstitut Oberwolfach in Germany to be used as stipend/travel for visitors from Japan,

- 1,000,000 Yen grant each year from 1996 till 2000 to the Mathematical Society of Japan to be used for its annual International Research Institute,

- 1,000,000 Yen grant each year from 1996 till 2000 to the Research Institute for Mathematical Sciences, Kyoto University to be used for its annual Project Research,

- A mathematical research exchange program between Japan and Vietnam,

- A mathematical research exchange program between Japan and Korea,

- A grant to the American Mathematical Society for translating good mathematics books in Japanese into English and making them available at reasonable price.

Due to the regulations coverning Japanese foundations, these grants had to be related to Japan in some respect or other. 


\section{The Educational Project for Japanese Mathematical Scientists}

This project was started in 1980 even before the establishment of JAMS and was continued until 1992, through the cooperation of people in the business community and the Japan Society for the Promotion of Science. The aim was to bring up creative mathematical scientists who could be world leaders in the twenty-first century.

Over the years, twenty talented young Japanese altogether were sent through this project to universities such as Harvard, Princeton, Rutgers, Yale, Edinburgh, Columbia, Brown, Oxford, Duke, UCLA and Northwestern, for graduate study in mathematics, statistics, computer science, mathematical economics, biology and medicine, for a few years with full scholarship for tuition and living expenses. After successful completion of their graduate studies, they have been quite active in research and business. Considerable number of them are now professors and associate professors in universities in Japan or overseas.

Aside from them, many other talented young Japanese were sent overseas for shorter periods for research or study in mathematical sciences.

\section{"Suuri no Tsubasa" and "Yugen Club"}

A week-long summer seminar called "Suuri no Tsubasa" (literally translated as "Wings of Mathematical Sciences") has been held every year since 1980. Each year about fifty talented young students are invited from highschools and colleges all over Japan (sometimes from overseas, as well). Lectures are given by established research scientists in the forefront, including Nobel laureates, not only in mathematics but also in physics, chemistry, biology, medicine, computer science, engineering, etc. According to Professor Hironaka, he was immensely inspired by Norbert Wiener and Claude Shannon he could meet in his youth, and wanted to share that experience with young people. He hoped to cultivate mathematical scientists with wider perspective.

The seminar provides a rare opportunity for talented young people to get to know one another, aside from getting to know in person active researchers in the forefront.

Past participants organized in 1982 an alumni association called "Yugen Club" ("Yugen" means "Puits de Science", a phrase coined by the late Dr. Ken-ichi Fukui, Nobel Laureate in Chemistry and a close friend of Hironaka's). The membership now is around 1,500. Most of the older members are now quite active in the forefront of mathematical sciences, medicine, bioscience, computer science, engineering, etc. Except in early years, members of the club have been taking care of the organization of the "Suuri no Tsubasa" summer seminar each 
year. They also give lectures on what they are up to, and organize workshops in smaller groups lasting till early morning hours.

First five seminars until 1984 (when JAMS was established) were organized by a private corporation called "Hironaka Education Institute". The sixth through twenty-second seminars until 2001 were organized by JAMS. Then in October, 2001, now well-established members of "Yugen Club" obtained approval from the Japanese Government to form a non-profit organization (NPO) called "Suuri no Tsubasa". One of its aims is to bring up leaders of the next generation in mathematical sciences. Since 2002, the NPO has been organizing the summer seminar. Although Professor Hironaka continues to participate in the seminar as one of the main lecturers, there is basically no further need in financial assistance from JAMS.

This is one of the indications of how Professor Hironaka's dreams have come true in almost thirty years. Professor Hironaka succeeded in bringing up so many extremely young talents well-versed in mathematical sciences, who not only are active in the forefront, but also will, in turn, keep on bringing up further new generations of talented people.

Since 1992, Professor Hironaka together with Professor Péter Frankl has also been cultivating much younger mathematical talents among pupils in elementary schools and junior high schools in Japan and overseas through activities such as "Arithmetic Olympics". 